\title{
Integrating spirituality into mental health rehabilitation
}

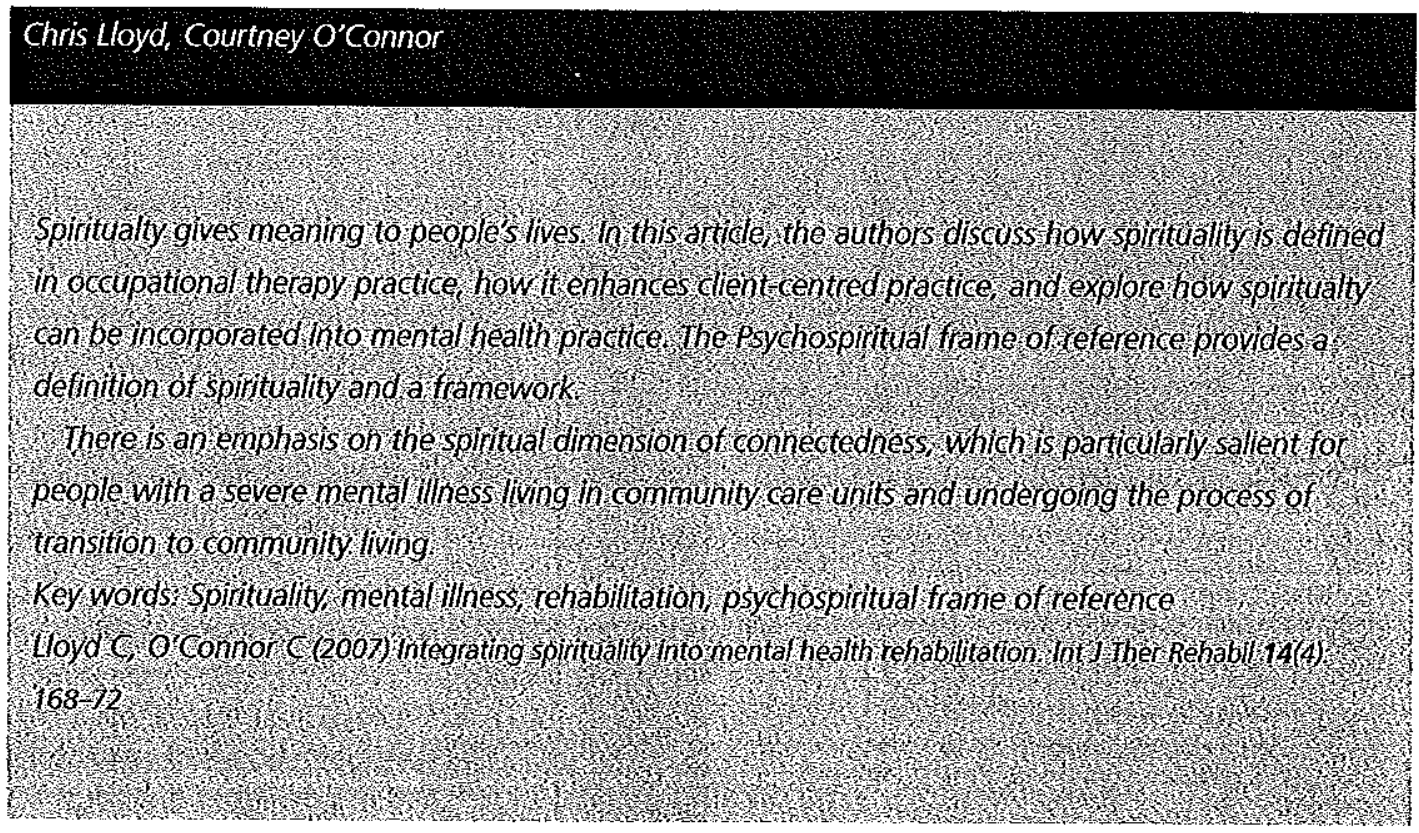

$\mathrm{W}$ hen considering the role of spirituality in occupational therapy practice, a critical task involves an awareness of what is intended and understood by the term 'spirituality'. Definitions of spirituality vary throughout the literature and practice models, complicating the task of incorporating spirituality into daily practice.

Some definitions of 'spirituality' that demonstrate this variety and allude to the common ground between spirituality and occupational therapy practice include:

'The experience of meaning in everyday

life.' (Urbanowski and Vargo, 1994)

Chris Lloyd is Senior

Lecturer, Division of Occupational Therapy, University of Queensland, St Lucia Q 4072, Courtuey O'Connor is Occupational Therapist, Disability Services Queensland, Brisbane, Australia

Correspondence to: C Lloyd

Lloyd@onthenet.com.au
'Sense of harmony within the self and between self, nature, others and in some cases, an ultimate other. (Chapparo and Ranka, 1997)

And that which:

'Seeks an existing mystery to life; inner conviction; hope and meaning.' (Chapparo and Ranka, 1997)

'The essence of a person expressed in daily actions, as influenced by values, belief systems, and socio-cultural background.' (Egan and De Laat, 1994)
'A pervasive life-force, manifestation of a higher self, source of will and selfdetermination and a sense of meaning, purpose and connectedness that people experience in the context of their environment.' (Canadian Association of Occupational Therapists, 1997)

'A quality that ultimately makes us who we are and our universe what it becomes.' (Kang, 2003)

Hammel (2001) highlighted the concept of 'intrinsicality' to:

'Identify the notion of a personal philosophy of meaning that informs life choices and life satisfaction."

The concepts 'meaning' and 'life' are also referred to and reflected in some of the definitions of spirituality:

'Participating in occupation creates and affirms meaning in life.' (Christiansen, 1997)

The above definitions are valuable examples, substantiating the idea that spirituality can be considered and incorporated into occupational therapy practice, with the aim of enhancing client-centred care for those individuals who may be suffering from a mental health disorder. 


\section{PRACTICE MODELS}

Some practice models consider spirituality as a central component, however, current literature suggests further clarification and development is necessary for the role of this essential concept to be well understood and applied. For instance, spirituality has always been considered a vital aspect of the Canadian Model of Occupational Performance (CMOP) (Canadian Association of Occupational Therapists (CAOT), 1997).

Spirituality is placed as a central concept at the core of the person dimension:

'Spirituality is at the heart of assessing

which occupations are meaningful to

clients, and in building meaningful

occupation into targeted outcomes,

action plans and implementation:

(CAOT, 1997)

Hammel (2001) recommended that the occupational therapy profession should employ the term 'intrinsicality' in an effort to decrease the substantial uncertainty currently surrounding the concept and application of spirituality in occupational therapy practice.

The authors believe that the psychospiritual (PSI) frame of reference developed by Kang (2003) provides a working definition of spirituality and a framework to support the role of spirituality in occupational therapy practice.

Kang (2003) suggests the CMOP (CAOT, 1997), the Occupational Performance Model - Australia (Chapparo and Ranka, 1997), the Model of Human Occupation (Kielhofner, 1995), and the Model of Wholeness and Reconstitution (do Rozario, 1997) are models that address spirituality either indirectly or as a central component. However, the author concluded that these models:

'Do not specifically offer practical methods for enabling spirituality in an occupational therapy setting.' (Kang. 2003)

Resulting from this conclusion Kang (2003) attempted to provide this structure within the PSI framework.

\section{PSYCHOSPIRITUAL FRAME OF REFERENCE}

Both spirituality and occupation are core features of PSI. Kang (2003) describes spirituality as:

'An integral harmony of six dimensions...

Becoming, meaning, being, centredness,

connectedness, transcendence.'

The framework suggests that spiritual fulfilment can exist at both an individual and community level when:

\section{'People are able to become what} they want to be, to find authentic meaning and purpose in life, to be fully themselves in each moment, to abide in inner stability and knowledge of one's centre, to lovingly and compassionately connect with the larger matrix of life, and to transcend limitations of self and self's constructions.' (Kang, 2003)

PSI suggests the above dimensions of spirituality can be embedded in all occupational forms, and participation in both generic and spiritual occupations can enhance spiritual fulfilment. Kang (2003) defined generic occupations as 'daily occupations', and spiritual occupations as:

'Activities specifically imbued with spiritual meanings and effects that have been performed by human beings over many generations and across all cultures.' Kang (2003) proposes that generic and spiritual occupations facilitate:

\section{- Occupational abundance}

Occupational function

Occupational balance

Occupational justice.

These, in turn, can contribute to spiritual fulfilment. Occupational abundance refers to communities where a rich number of generic and spiritual occupations are accessible, and occupational justice calls for equitable opportunities and means to engage in these occupations. PSI promotes alternating between different modes of doing, being and becoming to achieve occupational balance, and suggests that supporting people to maintain or enhance their ability to participate in occupations improves occupational function (Kang, 2003). PSI systematically defines spirituality and promotes the enablement of spirituality through occupation.

\section{Case example: Community care units in} Australia

In Queensland, Australia, people with mental disorders can access rehabilitation services through community care units (CCUs). These facilities provide non-hospital based extended inpatient services to those with mental health problems, in cluster housing accommodating up to 20 people in single and twin room accommodation (Queensland Health, 1996a). The staffing profile in CCUs is equivalent to that in hospital-based extended inpatient units, consisting of nursing, allied health, medical, administration and support staff (Queensland Health, 1996b), requiring committed teamwork from all staff.

The 10-year mental health strategy for Queensland states that (Queensland Health, 1996a): 
'The focus of (extended inpatient) services is inclusion in the local community, and individual planning to enable enhancement of community living skills, independence and maximizing the quality of life.'

Occupational therapists who are involved in providing rehabilitation, assist people to acquire the skills necessary for living independently in the community.

Mental health patients living in CCUs participate in programs that address a wide range of basic day-to-day living skills and have the opportunity to practice these skills in the environments in which they expect to connect once discharged. Acknowledging and encouraging PSI dimensions of spiritual fulfilment throughout the occupational therapy process would assist people to make this transition.

Despite the focus on CCUs, occupational therapists working in institutional environments or rehabilitation would be able to apply the concept of spirituality discussed here.

'Connectedness' is an element of spirituality particularly important in the CCU setting. When describing 'connectedness' PSI refers to:

'A sense of "interbeing", where the self existing as a totality of family, culture, community, society, ecology, and the cosmos, is experienced.' (Kang, 2003)

Aspects of connectedness will change substantially for people who are moving from an institational setting to the community. The individual with mental health problems and the occupational therapist can work together to identify which of the aspects of connectedness are potentially going to be affected, and develop strategies and skills to assist with the transition. Some skills that may be useful include:

Communication skills

- Social interaction

Support networking

Anxiety and stress management

Awareness of fitness and leisure resources.

\section{COLLABORATIVE PARTNERSHIPS}

The therapist is concerned with developing and maintaining collaborative partnerships with those with mental health disorders and their carers, paying attention to the significance of 'connectedness' in the CCU setting. This may include (Ford et al, 1999):

Actively seeking to understand the lived experience of individuals with mental health issues and carers

Appreciating the contribution of relationship and partnership
Supporting and implementing patient and carer participation policies, guidelines and initiatives. Urbanowski and Vargo (1994) drew attention to the importance of involving in the therapy process significant others with whom the individual with mental health issues shared daily activities.

The authors stated that:

"It is not only the spirituality of the individual that is affected by disability, but the spirituality of those who are part of the environment of the individual.'

(Urbanowski and Vargo, 1994)

Thus it is important that services recognize and support the families and carers of those with mental illnesses.

It may be seen as essential that such individuals are empowered to make decisions regarding the type of communities in which they hope to become a part, and how they wish to engage in these communities.

\section{ASSESSMENT AND ESTABLISHING VALUE-ORIENTED GOALS}

Spiritually sensitive assessment data can be used to work collaboratively with individuals to develop value-oriented goals that are personally meaningful. A core philosophical belief of the profession that occupational therapists aim to implement in practice suggests that engaging in meaningful activities positively influences quality of life. In addition to promoting people to engage in meaningful occupations, giving further meaning to these through acknowledging spirituality may result in improved, more effective and lasting therapy outcomes (Engquist et al 1997; Farrar; 2001; Corrigan et al, 2003).

Realistic, patient valued goals offer a motivational factor toward achieving goals (Clouston, 2003). To understand the values, beliefs and experiences of the person with mental health problems, individual reports must be accepted as the most relevant source of information (Law, 2001). Law (2001) suggested open-ended assessments provide the greatest opportunities to gain insight into areas meaningful to the client. The author proposed that the following instruments may be useful in this process:

The occupational performance history interview (OPHI)

The occupational questionnaire $(\mathrm{OQ})$

- The occupational self assessment (OSA)

m The COPM

The satisfaction with performance scaled questionnaire (SPSQ).

Clear documentation of assessment information, goals and progress is an organization expectation, 
and can be very useful in substantiating the merit of value-driven goals.

The PSI framework states the six dimensions of spirituality flow 'along an ever-expanding contin$\mathrm{umm}^{3}$ (Kang, 2003) and assessment of spirituality should take place throughout the entire occupational therapy process. Exploring all six dimensions of the PSI's construct of spirituality:

- Becoming

Meaning

- Being

- Centredness

Connectedness

- Transcendence.

Would encourage goals that convey the individual's reality and needs. Narrative reasoning and life stories are considered useful therapeutic tools to assist consumers and therapists explore their spirituality (Kirsh, 1996; Davidson et al, 1997; Hvalsoe and Josephsson, 2003). A narrative approach enables an understanding of meaning and purpose in one's life (Kirsh, 1996).

\section{INTERVENTION}

Engaging in meaningful activities is a core feature of occupational therapy intervention. For therapists to understand what occupations are meaningful to individuals with mental health disorders, they must spend time becoming familiar with the framework that patients use to interpret their own life and daily activities (Urbanowski and Vargo, 1994; Christiansen, 1997). Hammel (2001) suggested that to uphold the occupational therapy philosophy of client-centred practice, the values that inform life choices need to be addressed.

Spirituality has been recognized as an essential component to be included by the occupational therapy profession in client-centred practice (Kirsh, 1996).

Mental health patients and therapists can discover qualities that guide their occupational choices through considering PSI spiritual dimensions, particularly:
aecoming
a Meaning
Being
Centredness.

Identifying these qualities provides a foundation for incorporating meaningful activities into an individual's day and cultivating spiritual fulfilment (Kang, 2003). Employing the PSI framework to explore and acknowledge the individual's spirituality presents opportunities for consumers to discover and share what activities are meaningful to them, and subsequently enables the therapist to engage in client-centred practice.
The onset of psychiatric disability is a traumatic experience that may be experienced as a profound disconnection from the self, community participation, and from a sense of meaning and purpose (Young and Ensing, 1999; Spaniol, 2001). Individuals with a mental illness may also experience disconnection because of the lack of knowledge, skills, and support necessary to integrate their experience (Spaniol, 2001). Having a mental illness often impacts on an individuals ability to cope with life in general.

\section{RECOVERY}

A study by Young and Ensing (1999) found that recovery involves using some form of spirituality that gives hope and meaning to life. Hope involves investing one's life and future with meaning. As spirituality provides a framework for understanding and imbuing one's life with meaning and purpose, exploring spirituality can be considered a key foundation for fostering hope in life (Corrigan, et al, 2003). Helfrich et al (1994) also identified that discovering meaning, purpose and hope in life are core aspects of interventions, which will assist in motivating consumers to engage in therapy. For example, a study by Corrigan et al (2003) found that people with serious mental illness who selfidentified as being spiritual had better outcomes related to recovery.

In the study 'spiritual' was defined as:

'Thinking about one's self as part of

a larger spiritual force... And as the

feeling or experience of connectedness/

relationship/oneness with God, a spirit,

nature, unifying force.' (Corrigan et al, 2003)

Recovery outcomes included:

Objective and subjective social inclusion

Quality of life

Hope

- Empowerment.

Corrigan et al (2003) also found that self-report of spirituality led to significantly less psychiatric symptom reports, and was related to self impressions that the person was acting more effectively in his or her daily life. They suggested that failure to inquire into consumers' spiritual beliefs may lead to failure to make use of the strong power of these beliefs towards therapeutic ends.

\section{CONCLUSION}

Dimensions of spirituality assist individuals in discovering meaning and purpose in their lives, which is an important aspect of the occupational therapy process. The literature provides several, at times, 
contradicting definitions of the construct of spirituality and its role in occupational therapy practice. Until the profession adopts frameworks that provide clear definitions of this concept and tools to enable its application, practitioners will continue to experience difficulties incorporating spirituality into daily practice.

The authors have proposed that Kang's (2003) PSI framework offers a helpful approach to employ spirituality in practice. People are unique beings who draw from a diverse range of frameworks to derive meaning and purpose from life. Beconing aware of what individuals value and interpret as meaningful in life is essential to client-centred practice, and a central theme of PSI's construct of spirituality.

Acknowledging spirituality empowers those with mental health problems to discover what frameworks and activities are meaningful to them and incorporate these values into the entire therapy process. IJTR

Conflict of interesi: none

Canadian Association of Occupational Therapists (1997) Enabling occupation: An occupational therapy perspective. Ottawa: CAOT Publication ACE

Chapparo C, Ranka J (1997) Occupational Performance Model (Australia) Monograph I. Sydney: Occupational Performance Network, University of Sydney

Christiansen C (1997) Acknowledging a spiritual dimen-

\section{KEY POINTS}

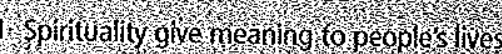

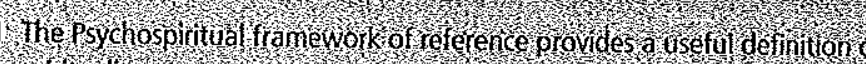
spintuality

The splitual dimens on of connectedness is exoloted and hevns of

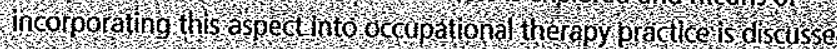

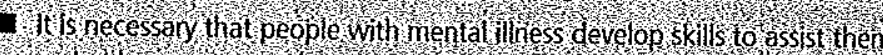
moke hetransition rom the histitutional setting to he comnunity sion in occupational therapy practice. American Journal of Occupational Therapy 51: $167-72$

Clouston T (2003) Narrative methods: Talk, listening and representation. British Journal of Occupaional Therapy 66: $136-42$

Corrigan P, McCorkle B, Schell B, Kidder K (2003) Religion and spirituality in the lives of people with serious mental illness. Community Mental Healih Journal 39: 487-99

Davidson H, Spencer J, White V (1997) Helping clients develop hopes for the future. American Journal of Occupational Therapy' 51: 191-8

Do Rozario $\mathrm{L}$ (1997) Spirituality in the lives of people with disability and chronic illness: A creative paradigm of wholeness and reconstitution. Disability and Rehabilitation 19: $427-34$

Egan M, De Laat M (1994) Considering spirituality in occupational therapy practice. Canadian Journal of Occupational Therapy 61: $95-101$

Engquist DR, Short-DeGraff M, Gliner J, Oltjenbruns K (1997) Occupational therapists' beliefs and practices with regard to spirituality and therapy. American Joumal of Occupational Therapy, 51: 173-80

Farrar JR (2001) Addressing spirituality and religious life in occupational therapy practice. In: A. Burkhardt \& J. Carlson (Eds.), Complementary therapies in geriatric practice: Selected topics. New York: The Haworth Press, Inc. 65-85

Ford L, Dorries V, Fossey E et al (1999) Australian competency' standards for occupational therapists in mental health. Fitzroy: OT AUSTRALIA

Hammel W (2001) Intrinsicality: Reconsidering spirituality, meaning(s) and mandates. Canadian Journal of Occupational Therapy 68: 186-94

Helfrich C, Kielhofner G, Mattingly C (1994) Volition as narrative: Understanding motivation in chronic illness. American Joumal of Occupational Therapy 48:311-17

Hvalsoe B, Josephsson S (2003) Characteristics of meaningfil occupations from the perspective of mentally ill people. Scandinavian Journal of Occupational Therapy 10: 61-71

Kang C (2003) A psychospiritual integration frame of reference for occupational therapy. Part 1. Conceptual foundations. Ausralion Occupational Therapy Journal 50: 92-103

Kielhofner G (1995) A model of human occupation: Theory and application (2nd edn). Batimore: Williams and Wilkins

Kirsh B (1996) A narrative approach to addressing spirituality in occupational therapy: Exploring personal meaning and purpose. Canadian Journal of Occupational Therapy, 63: $55-6$

Law M (2001) Measuring occupational performance: Supporting best practice in occupational therapy. Thorofare, N.J: Slack.

Queensland Heaith (1996a) Extended inpatient services. 10 year mental health strategy for Queensland. [Electronic Version]. Brisbane, Queensland Health

Queensland Health (1996b) Extended treatment and rehabilitation inpatient unit. Building guidelines for QId mental heatth facilities. [Electronic Version]. Brisbane, Queensland Health

Spaniol L (2001) Spirituality and connectedness. Psychiatric Rehabilitation Journal 25: 321-2

Urbanowski, R, Vargo J (1994) Spirituality, daily practice, and the occupational performance model. Canadian Joumal of Occupational Therapy, 6: 88-94

Young S, Ensing D (1999) Exploring recovery from the perspectives of people with disabilities. Psychiatric Rehabilitation Journal 22: 219-31

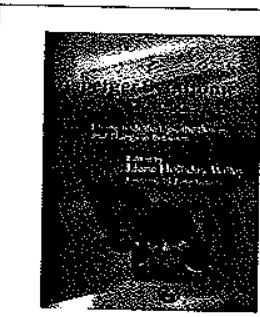

\section{Would you like to} be a book reviewer?

If so, please email tanya.f@markallengroup.com with your research interests.

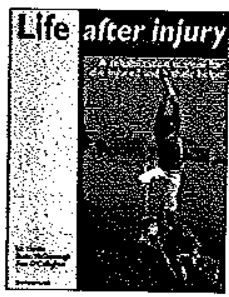

